\title{
Article \\ Endothelium-Independent Relaxation of Vascular Smooth Muscle Induced by Persimmon-Derived Polyphenol Phytocomplex in Rats
}

\author{
Risa Kudo*(D), Katsuya Yuui (D) and Shogo Kasuda
}

check for updates

Citation: Kudo, R.; Yuui, K.; Kasuda, S. Endothelium-Independent Relaxation of Vascular Smooth Muscle Induced by

Persimmon-Derived Polyphenol

Phytocomplex in Rats. Nutrients 2022,

14, 89. https://doi.org/10.3390/

nu14010089

Academic Editors: Antonella Di Sotto and Silvia Di Giacomo

Received: 2 November 2021

Accepted: 23 December 2021

Published: 26 December 2021

Publisher's Note: MDPI stays neutral with regard to jurisdictional claims in published maps and institutional affiliations.

Copyright: (c) 2021 by the authors. Licensee MDPI, Basel, Switzerland. This article is an open access article distributed under the terms and conditions of the Creative Commons Attribution (CC BY) license (https:// creativecommons.org/licenses/by/ $4.0 /)$.
Department of Legal Medicine, Nara Medical University, 840 Shijocho, Kashihara 634-8521, Nara, Japan; yuui@naramed-u.ac.jp (K.Y.); skasuda@naramed-u.ac.jp (S.K.)

* Correspondence: rkudo@naramed-u.ac.jp; Tel.: +81-744-29-8843

\begin{abstract}
The vasorelaxant effect of polyphenols is well known, and the mortality rate due to coronary artery disease is low in people who consume polyphenol-containing foods. We aimed to elucidate the mechanism by which polyphenols derived from persimmon juice (PJ) and persimmon leaves (PLs) induce vasorelaxation and suppress vasocontraction in the superior mesenteric arteries isolated from male Sprague Dawley rats. Vasocontraction was induced with $1 \mu \mathrm{M}$ phenylephrine, and polyphenol-induced vasorelaxation was expressed as a percentage of the previous tone induced by phenylephrine. PJ powder (100 mg/L) induced higher levels of vasorelaxation (mean \pm standard error of the mean, $88.6 \% \pm 4.4 \%)$ than PLs powder $(1 \mathrm{~g} / \mathrm{L} ; 72.0 \% \pm 10.8 \%)$. Nitric oxide pathway inhibitors (NG-nitro-L-arginine methyl ester + carboxy-PTIO) did not affect persimmon-derived polyphenolinduced vasorelaxation, whereas potassium chloride, tetraethylammonium, and potassium-channel inhibitors did. Vasorelaxation was endothelium independent with both extracts. Phenylephrineinduced vasocontraction was suppressed by pretreatment with PJ and PLs powder, even when inositol triphosphate-mediated $\mathrm{Ca}^{2+}$ release and extracellular $\mathrm{Ca}^{2+}$ influx were inhibited. These results suggest that persimmon-derived polyphenol phytocomplex cause vasorelaxation and inhibit vasocontraction through hyperpolarization of smooth muscle cells. Persimmon-derived polyphenols may be able to prevent cardiovascular diseases caused by abnormal contraction of blood vessels.
\end{abstract}

Keywords: persimmon polyphenols; hyperpolarization; rat; superior mesenteric artery; vascular smooth muscle; vasorelaxation; potassium channels

\section{Introduction}

Polyphenols contained in various foods are known to have a wide range of physiological effects, such as antihypertensive, antioxidative, anti-inflammatory, and anti-allergic effects, suppressing carcinogenesis and blood glucose elevation, and ameliorating cardiovascular disease and metabolic abnormalities [1-4]. There is a negative correlation between the frequency of intake of polyphenol-rich foods (tea, grapes, apples, cocoa, onions, strawberries, etc.) and the risk of cardiovascular disease [5]. In addition, clinical studies conducted on the effects of polyphenols on the circulatory system, revealed that ingestion of polyphenols is effective in lowering blood pressure in patients with mild hypertension [6]. Furthermore, polyphenols ameliorate dyslipidemia and insulin sensitivity [7-11].

Polyphenols are also known to improve the ability of vascular endothelial cells to control the vascular tone and protect the cardiovascular system [12,13]. Polyphenols contained in many foods induce endothelium-dependent vasorelaxation, suppress vasocontraction, and exert antihypertensive effects $[14,15]$. In experiments with isolated arteries, it has been reported that endothelium-dependent vasorelaxation induced by polyphenols is mainly mediated via the nitric oxide (NO) pathway [16-19]. Furthermore, in peripheral arteries, polyphenols reportedly cause vasorelaxation via the endothelium-derived hyperpolarizing factor $(\mathrm{EDHF})$ in addition to NO [20-22]. 
The fruits and leaves of persimmons, which are produced in Japan, are rich in polyphenols and were found to exert antihypertensive, antioxidative, anti-inflammatory, and blood glucose-lowering effects [23-25]. Regarding vascular function, polyphenols derived from persimmon leaves (PLs) reportedly cause NO-mediated vasorelaxation in conduit arteries such as the aorta [26], but the mechanism of peripheral artery relaxation remains unclear. Furthermore, to the best of our knowledge, there are no studies on the effects of polyphenols derived from persimmon juice (PJ) on peripheral arteries. We hypothesized that PJand PLs-derived polyphenols have strong vasorelaxation and vasocontraction inhibitory effects on rat peripheral arteries due to vascular endothelium independence (i.e., vascular smooth muscle hyperpolarization) rather than vascular endothelial cell-derived NO.

\section{Materials and Methods}

\subsection{Preparation of PJ and PLs Powder}

Immature, astringent Japanese persimmon (Diospyros kaki) fruits and leaves of the Hiratanenashi cultivar, harvested in Nara Prefecture, were processed to obtain PJ and PLs powder.

The tannin-containing PJ was prepared to obtain the so-called "Kakishibu" powder. The harvested, immature fruits were treated with $0.2 \%(v / w)$ ethanol for 5 days to solubilize the polyphenols. Treated fruits were crushed, immersed in water, and stored at room temperature for 2 days. Thereafter, the supernatant, containing soluble components such as sugar, was removed. Water was added to the residue containing the polyphenols, and the mixture was heated to $120^{\circ} \mathrm{C}$ for $30 \mathrm{~min}$ to extract the polyphenols. The extract was filtered, evaporated in vacuo, and drum dried at $160{ }^{\circ} \mathrm{C}$ to produce a powder. PLs powder was obtained from persimmon leaves that were roasted for sterilization, dried, and pulverized.

The catechin (tannin) concentrations in the PJ and PLs powders were $64.0 \%$ and $5.23 \%$, respectively, as measured by using the iron-tartrate colorimetric method [27]. These powders were prepared and provided by Ishii-Bussan, Inc. (Nara, Japan) and stored at $-20^{\circ} \mathrm{C}$ until use.

\subsection{Estimation of Catechin Components in PJ and PLs}

PJ and PLs powders were dissolved in distilled water $(10 \mathrm{~g} / \mathrm{L})$, filtered through $0.22 \mu \mathrm{m}$ membrane filters, and used for further experiments. A Shimadzu 8045 triple quadrupole mass spectrometer with a probe electrospray ionization (PESI) ion source (Shimadzu, Kyoto, Japan) was used for the direct detection of catechin components. The samples were placed directly on a dedicated plastic sample plate and set on the PESI ion source [28]. The probe needle was lowered such that the needle tip touched the sample and then was raised to apply a high voltage for ionization. This vertical movement was repeated, and the generated ions were introduced into the tandem mass spectrometry (MS/MS) system. The PESI-MS/MS conditions were set as follows: probe-applied voltage, $2.3 \mathrm{kV}$; cycle time for probe movement, $160 \mathrm{~ms}$; desolvation line temperature, $250{ }^{\circ} \mathrm{C}$; heat block temperature, $50{ }^{\circ} \mathrm{C}$; and polarity, negative. The probe position (distance from the tip of the needle to the center of the MS inlet) was set at $2 \mathrm{~mm}$ in the $\mathrm{y}$ axis and $2.5 \mathrm{~mm}$ in the $\mathrm{x}$ axis. The product ion (Pl) spectra of the compounds were measured in the multiple reaction monitoring (MRM)$\mathrm{Pl}$ scan mode. The collision energies were adjusted to optimize the product ion signal to be $-27,-30,-33,-41 \mathrm{eV}$ for (-) epigallo-catechin-3-gallate (EGCg), (-) epicatechin3-gallate (ECg), (-) epigallocatechin (EGC), and (-) epicatechin (EC). The MRM mode was used to monitor the transition of the deprotonated molecule at $\mathrm{m} / \mathrm{z} 457.0 \rightarrow 168.8$ (EGCg), $441.0 \rightarrow 168.8$ (ECg), $305.1 \rightarrow 124.8$ (EGC), $289.1 \rightarrow 108.8$ (EC) [29]. The catechin composition ratios were calculated by integrating all peak areas of each compound using the built-in LabSolutions software (ver. 5.99 SP2, Shimadzu Corp., Kyoto, Japan). 


\subsection{Animal Procedures}

All protocols for the animal experiments were approved by the Animal Care Committee of Nara Medical University in accordance with the policies established in the NIH Guide for the Care and Use of Laboratory Animals (Permit No. 12689).

Male Sprague Dawley rats $(n=20,10-12$ weeks old and weighing 330-350 g; CLEA Japan, Inc., Tokyo, Japan) were placed in a quiet, temperature- and humidity-controlled room, and maintained in a $12 \mathrm{~h}$ light-dark cycle (08:00-20:00 light).

\subsection{Preparation of Rings of Isolated Superior Mesenteric Artery}

The rats were euthanized by exsanguination. Their superior mesenteric arteries (SMAs) were excised and the adherent connective tissues were removed. The SMAs were sectioned into rings of 1-1.5 $\mathrm{mm}$ in length that were arranged isometrically in vitro, as previously described [30]. Briefly, the rings were horizontally mounted on tension hooks (50 $\mu \mathrm{m}$ in diameter) in $4 \mathrm{~mL}$ organ baths containing Krebs-Ringer solution $(118 \mathrm{mM} \mathrm{NaCl}$, $4.7 \mathrm{mM} \mathrm{KCl}, 1.2 \mathrm{mM} \mathrm{MgSO}$, $1.2 \mathrm{mM} \mathrm{KH}_{2} \mathrm{PO}_{4}, 25 \mathrm{mM} \mathrm{NaHCO} 3,2.5 \mathrm{mM} \mathrm{CaCl}$, and $10 \mathrm{mM}$ D-glucose; $\mathrm{pH}$ 7.4). The solution was maintained at $37^{\circ} \mathrm{C}$ by using a thermally regulated water circuit, and continuously aerated with $95 \% \mathrm{O}_{2}$ and $5 \% \mathrm{CO}_{2}$.

\subsection{Tension Measurement}

SMAs were used in the present study to determine isometric tension, as there is considerable cumulative knowledge of their vascular function. Isometric tension was monitored with a force-displacement transducer (Signal Conditioner/MSC-2, Primetech Co., Tokyo, Japan), connected to one side of each tension hook, and documented with a pen recorder (Pantos Unicorder/U-228, Nihon Kohden Kohgyo Co., Tokyo, Japan). The SMA rings were suspended on the hooks, the tension was set to $0.2 \mathrm{~g}$, and the rings were stabilized in the organ baths at $37^{\circ} \mathrm{C}$ for $90 \mathrm{~min}$. The Krebs-Ringer solution was changed every $15 \mathrm{~min}$. The resting tension was maintained at $0.2 \mathrm{~g}$ throughout the experiment [31].

For studies of the endothelium-intact vessels, the rings were discarded if acetylcholineinduced relaxation was not $\geq 80 \%$. For studies of the endothelium-removed vessels, the endothelial cells were removed by rubbing the intimal surface with a stainless-steel wire. The endothelial cell removal was confirmed by the absence of relaxation when the vessel was exposed to $1 \mu \mathrm{M}$ acetylcholine.

None of the SMA rings were used for repeated measurements; rather, a single doseresponse test was performed on each ring. Various inhibitor combinations were tested using different SMA rings isolated from the same rat. Inhibitors were added to the bath $30 \mathrm{~min}$ before the addition of phenylephrine.

\subsection{PJ-and PLs-Induced Vasorelaxation}

Relaxant responses were studied in SMAs that had been precontracted with phenylephrine $(1 \mu \mathrm{M})$. After the contractions reached a plateau, PJ (0.1-100 mg/L) or PLs (0.1-1000 mg/L) powder was cumulatively added to the bath, and concentration-response curves were plotted. Relaxation was expressed as a percentage of the contraction in response to $1 \mu \mathrm{M}$ phenylephrine.

\subsection{Effect of PJ and PLs on Potassium Chloride- and Phenylephrine-Induced Vasocontraction}

PJ or PLs powder $(1 \mathrm{~g} / \mathrm{L})$ was added to the bath, and after $30 \mathrm{~min}$, phenylephrine (0.001-10 $\mu \mathrm{M})$ or potassium chloride $(0-80 \mathrm{mM})$ was added cumulatively. The shrinkage rate was calculated as a percentage of the shrinkage force $25 \mathrm{~min}$ after the addition of $60 \mathrm{mM}$ potassium chloride, which was tested in advance without the presence of PJ or PLs powder.

Phenylephrine-induced vasocontraction is triggered via the receptor-operated channelmediated pathway in smooth muscle cell membranes and the intracellular triphosphate (IP3)-mediated pathway in smooth muscle cells. To clarify which of these pathways were 
inhibited by PJ and PLs, we investigated the effects of PJ and PLs on phenylephrine-induced vasocontraction by inhibiting each pathway.

\subsection{Statistical Analyses}

All data are expressed as means \pm standard error of the mean. The biochemical and physiological parameters were analyzed statistically with one-way analysis of variance followed by Dunnett's test for comparison of experimental conditions with control conditions. Statistical significance was set at $p<0.05$.

\subsection{Chemicals and Drugs}

4-Aminopyridine, apamin, carboxy-PTIO, glibenclamide, $\mathrm{N} \omega$-nitro-L-arginine methyl ester hydrochloride, $(R)-(-)$-phenylephrine hydrochloride, and TRAM-34 were obtained from Merck KGaA (Darmstadt, Germany). Iberiotoxin, potassium chloride, and tetraethylammonium chloride were obtained from FUJIFILM Wako Pure Chemical Corporation (Osaka, Japan). Xestospongin C (XeC) was obtained from Abcam plc (Cambridge, UK).

\section{Results}

\subsection{Catechins Contained in PJ and PLS}

EC, ECg, EGC, and EGCg, were detected in the PJ and PLs samples. Their composition ratios were EC:ECg:EGC:EGCg = 3:1:11:2 in PJ and 11:1:22:1 in PLs (Figure 1).

a.

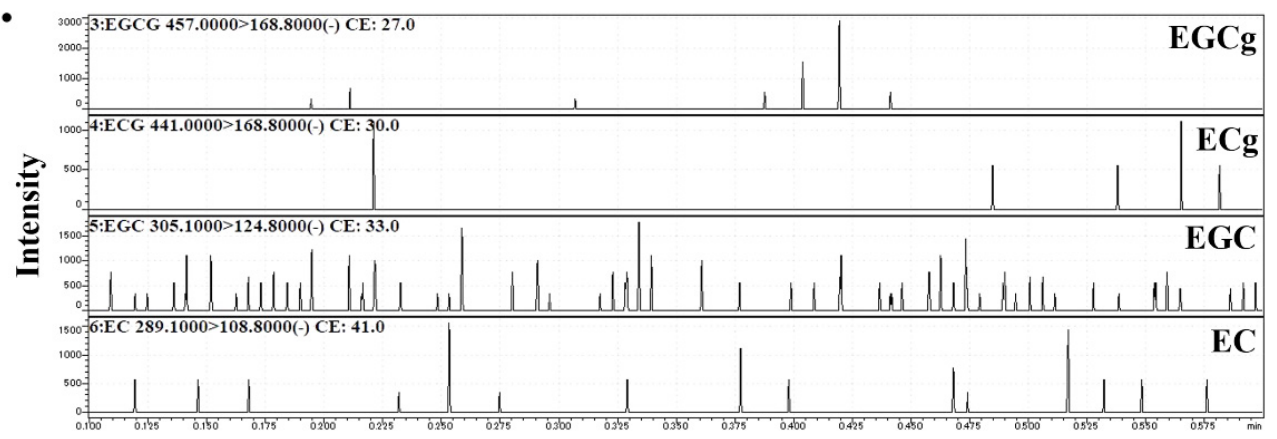

Retention Time (min)

b.

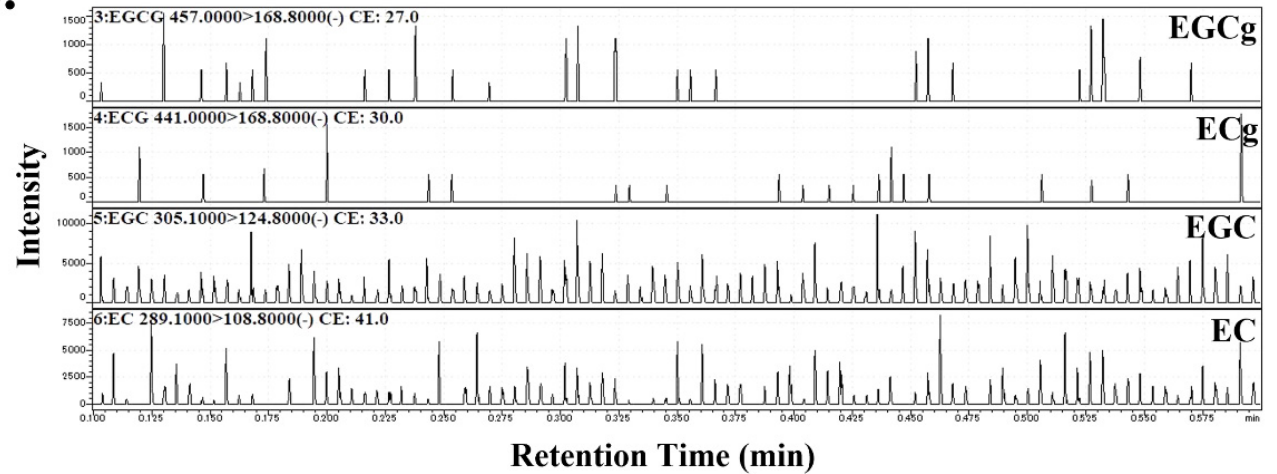

Figure 1. MRM chromatograms of (a) persimmon juice (PJ) and (b) persimmon leaves (PLs). The product ion ( $\mathrm{Pl})$ spectra of the compounds were measured in the multiple reaction monitoring (MRM)-Pl scan mode. The collision energies were adjusted to optimize the product ion signal as $-27,-30,-33,-41 \mathrm{eV}$ for (-) epigallo-catechin-3-gallate (EGCg), (-) epicatechin-3-gallate (ECg), $(-)$ epigallocatechin (EGC), and (-) epicatechin (EC). The MRM mode was used to monitor the transition of the deprotonated molecule at $\mathrm{m} / \mathrm{z} 457.0 \rightarrow 168.8$ (EGCg), $441.0 \rightarrow 168.8$ (ECg), $305.1 \rightarrow 124.8$ (EGC), $289.1 \rightarrow 108.8$ (EC). 


\subsection{Endothelium-Dependent Vasorelaxation Induced by PJ and PLs}

Following precontraction with phenylephrine, PJ and PLs induced dose-dependent relaxation of vessels. Maximum vasorelaxation effects were observed with $100 \mathrm{mg} / \mathrm{L}$ PJ powder $(88.6 \% \pm 4.4 \%)$ and $1 \mathrm{~g} / \mathrm{L}$ PLs powder $(76.4 \% \pm 6.7 \%)$. Thus, PJ induced higher levels of vasorelaxation than did PLs. These vasorelaxation effects were not altered by endothelium removal (Figure 2a,b, Table 1).

a.

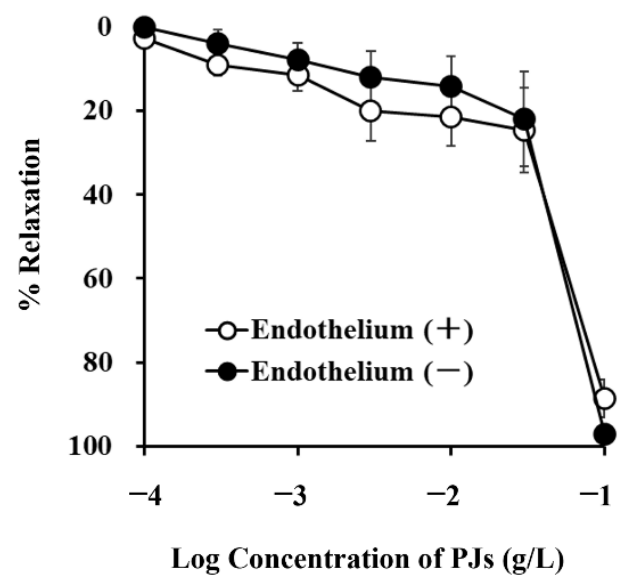

c.

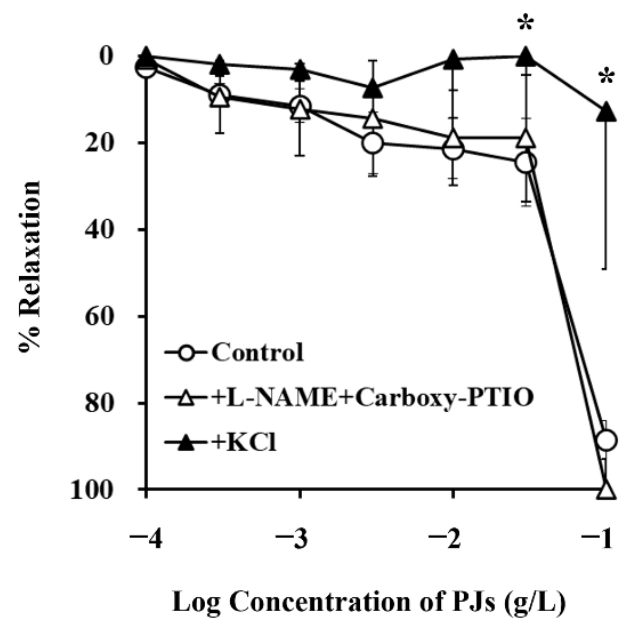

b.

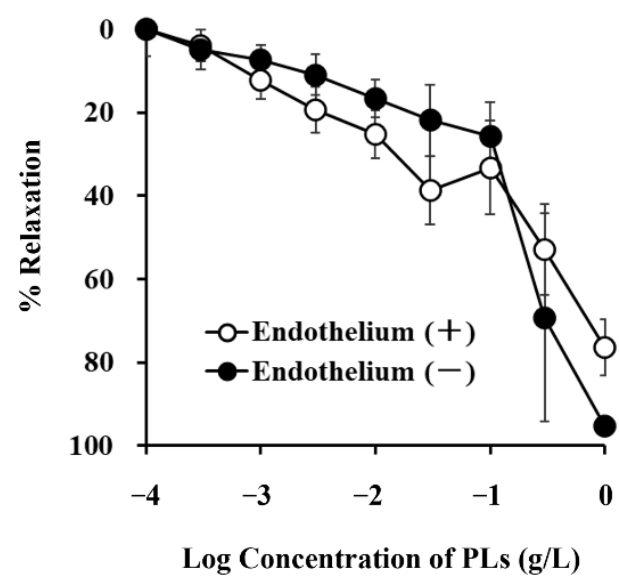

d.

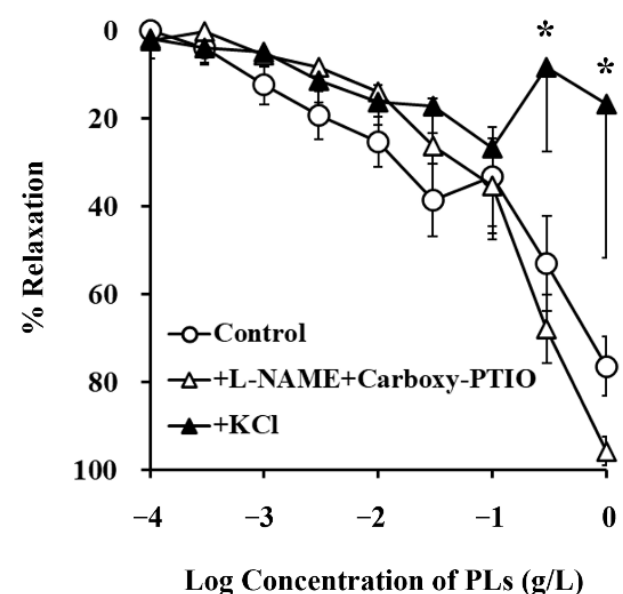

Figure 2. Concentration-response curves for $(\mathbf{a}, \mathbf{c})$ persimmon juice (PJ)- and $(\mathbf{b}, \mathbf{d})$ persimmon leaf (PLs)-induced vasorelaxation in rat superior mesenteric artery rings $(n=4-6)$. (a, b) These curves were constructed from experiments in the presence and absence of endothelium. (c,d) These curves were constructed from experiments in the absence (control) and presence of NG-nitro-L-arginine methyl ester (L-NAME; $1 \mathrm{mM})+$ carboxy-PTIO $(0.1 \mathrm{mM})$ and potassium chloride $(20 \mathrm{mM})$. Results (mean \pm standard error of the mean) are expressed as a percentage of the previous tone induced by phenylephrine $(1 \mu \mathrm{M}) .{ }^{*} p<0.05$ vs. the control (Dunnett's test). 
Table 1. Effects of various inhibitors on persimmon juice (PJ)- or persimmon leaf (PLs)-induced vasorelaxation in rat superior mesenteric artery rings.

\begin{tabular}{|c|c|c|c|c|}
\hline Inhibitors Added & \multicolumn{2}{|c|}{$\mathrm{PJ}(0.1 \mathrm{~g} / \mathrm{L})$} & \multicolumn{2}{|c|}{ PLs (0.3 g/L) } \\
\hline & $\%$ Relaxation & $p$ Value & $\%$ Relaxation & $p$ Value \\
\hline \multicolumn{5}{|l|}{ Endothelium (+) } \\
\hline none & $88.6 \pm 4.39$ & & $58.4 \pm 7.79$ & \\
\hline +L-NAME + carboxy-PTIO & $100.0 \pm 6.99$ & 0.97 & $72.6 \pm 6.58$ & 0.93 \\
\hline$+\mathrm{KCl}$ & $12.7 \pm 36.5^{*}$ & 0.0002 & $8.39 \pm 19.0 *$ & 0.05 \\
\hline \multicolumn{5}{|l|}{ Endothelium (-) } \\
\hline none & $97.1 \pm 0.28$ & $0.95^{1}$ & $69.2 \pm 25.0$ & $0.91^{1}$ \\
\hline$+\mathrm{TEA}$ & $48.4 \pm 21.1^{\dagger}$ & 0.03 & $12.5 \pm 12.9^{\dagger}$ & 0.04 \\
\hline +(1) 4-Aminopyridine & $97.0 \pm 0.46$ & 0.85 & $96.6 \pm 1.44$ & 0.99 \\
\hline +(2) Glibenclamide & $100.0 \pm 4.54$ & 0.89 & $90.3 \pm 4.35$ & 0.98 \\
\hline +(3) IbTX + apamin + TRAM-34 & $90.7 \pm 6.48$ & 0.74 & $18.2 \pm 0.11$ & 0.09 \\
\hline$+(1)+(2)+(3)$ & $49.7 \pm 11.4^{\dagger}$ & 0.03 & $20.2 \pm 11.5$ & 0.07 \\
\hline \multicolumn{5}{|c|}{$\begin{array}{l}\text { The inhibitors added were none, NG-nitro-L-arginine methyl ester (L-NAME } 1 \mathrm{mM})+ \text { carboxy-PTIO } \\
(0.1 \mathrm{mM}) \text {, potassium chloride }(20 \mathrm{mM}) \text {, tetraethylammonium }(\mathrm{TEA} 1 \mathrm{mM}),(1) 4 \text {-aminopyridine }(1 \mathrm{mM}) \text {, } \\
(2) \text { glibenclamide }(10 \mu \mathrm{M}),(3) \text { iberiotoxin }(\text { ibTX } 0.1 \mu \mathrm{M})+\text { apamin }(0.1 \mu \mathrm{M})+\text { TRAM- } 34(10 \mu \mathrm{M}) \text {, and } \\
(1)+(2)+(3) \text {. Relaxations }(\text { mean } \pm \text { standard error of mean) are expressed as a percentage of the previous } \\
\text { tone induced by phenylephrine }(1 \mu \mathrm{M}) .{ }^{*} p<0.05 \mathrm{vs} \text {. none in the presence of endothelium (Dunnett's test). } \\
{ }^{+} p<0.05 \text { vs. none in the absence of endothelium (Dunnett's test). }{ }^{1} p \text { values compared to none in the } \\
\text { presence of endothelium. } n=4-6 \text {. }\end{array}$} \\
\hline
\end{tabular}

NG-nitro-L-arginine methyl ester $(1 \mathrm{mM})$ and carboxy-PTIO $(0.1 \mathrm{mM})$, inhibitors of the NO pathway, did not inhibit PJ and PLs-induced vasorelaxation. Potassium chloride, at a concentration that depolarizes cell membranes $(20 \mathrm{mM})$ significantly inhibited PJ- and PLs-induced vasorelaxation (Figure 2c,d, Table 1). These results suggest that vasorelaxation induced by PJ and PLs is caused by hyperpolarization of vascular smooth muscle.

\subsection{Effect of Potassium-Channel Inhibitors on PJ- and PLs-Induced Vasorelaxation}

As endothelial cells were not involved in PJ- and PLs-induced vasorelaxation, we used endothelium-removed vessels to investigate the effects of various potassium-channel inhibitors on PJ- and PLs-induced vasorelaxation at the level of vascular smooth muscle.

Tetraethylammonium (TEA; $1 \mathrm{mM}$ ), a non-selective potassium-channel inhibitor, significantly inhibited PJ (0.1 g/L)- and PLs $(0.3 \mathrm{~g} / \mathrm{L})$-induced vasorelaxation (Figure $3 \mathrm{a}, \mathrm{b}$ and Figure $4 \mathrm{a}, \mathrm{b}$, Table 1).

None of the other potassium-channel inhibitors, $(1 \mathrm{mM} 4$-aminopyridine, a potent, non-selective, voltage-gated potassium-channel inhibitor; $10 \mu \mathrm{M}$ glibenclamide, a vascular, ATP-sensitive potassium-channel inhibitor; $0.1 \mu \mathrm{M}$ iberiotoxin $+0.1 \mu \mathrm{M}$ apamin $+10 \mu \mathrm{M}$ TRAM-34, calcium-activated potassium-channel inhibitors) inhibited PJ-induced vasorelaxation. However, in the presence of a combination of all these inhibitors, PJ (0.1 g/L)- and PLs ( $1 \mathrm{~g} / \mathrm{L})$-induced relaxation was significantly inhibited (Figure $3 c, d$ and Figure $4 a$, Table 1 ). 
a.

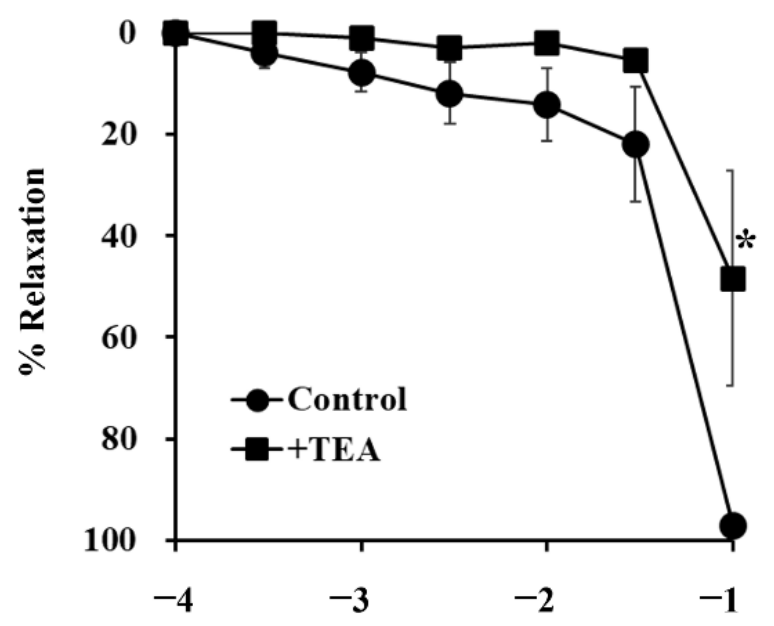

Log Concentration of PJs (g/L)

c.

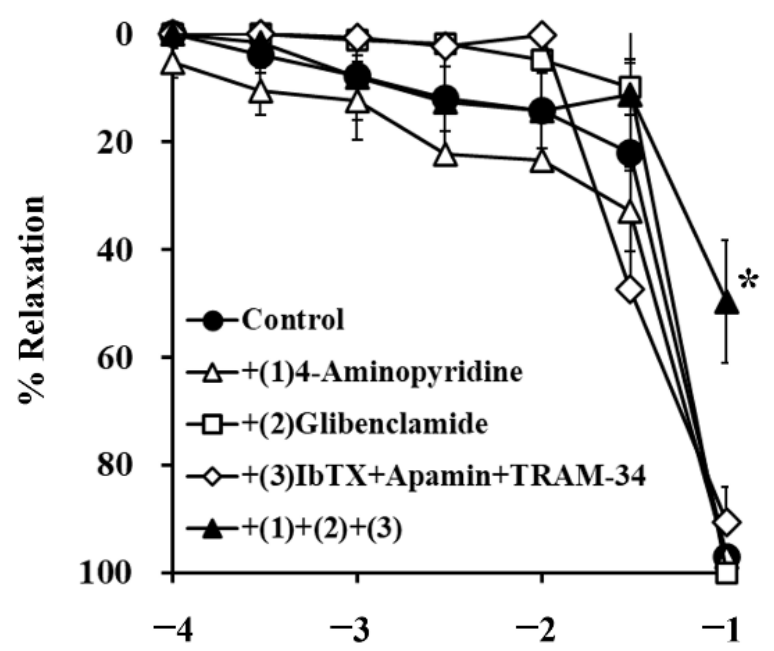

Log Concentration of PJs (g/L) b.

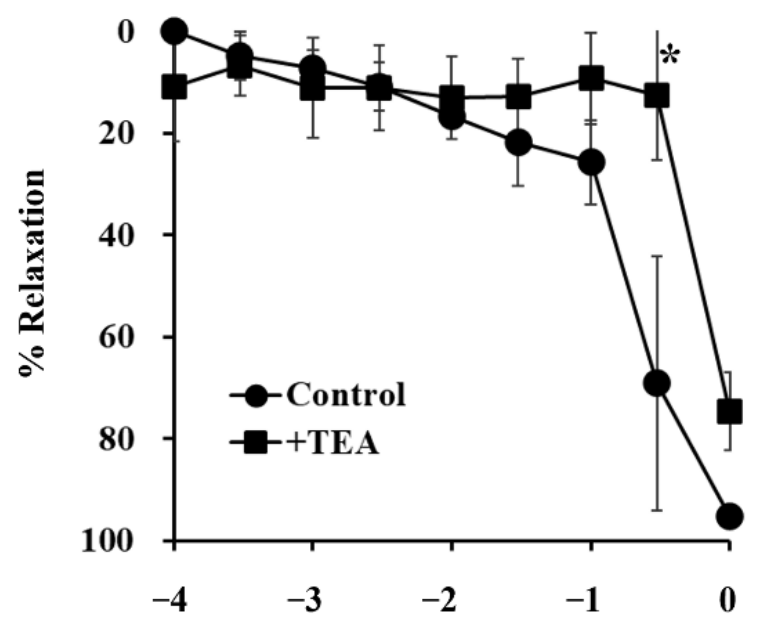

Log Concentration of PLs (g/L)

d.

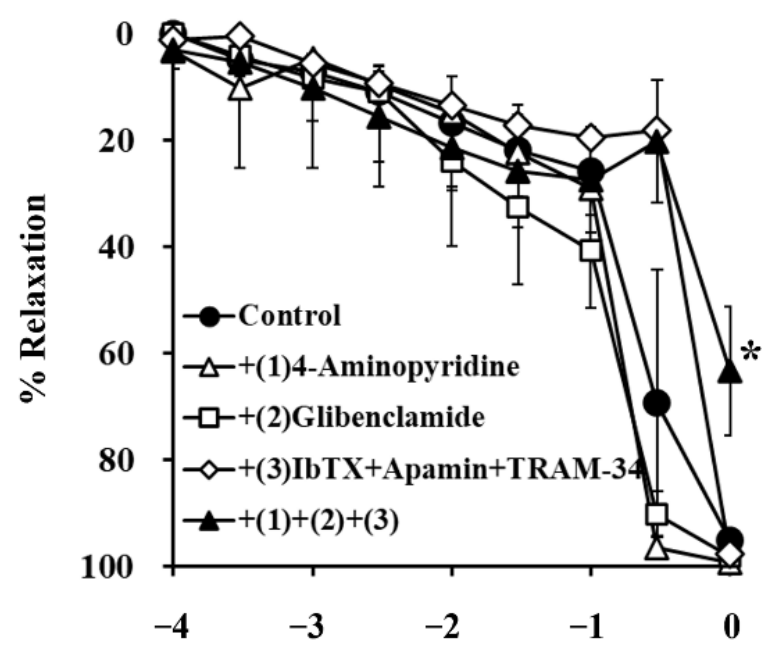

Log Concentration of PLs (g/L)

Figure 3. Concentration-response curves for $(\mathbf{a}, \mathbf{c})$ persimmon juice $(\mathrm{PJ})$ - and $(\mathbf{b}, \mathbf{d})$ persimmon leaf (PLs)-induced vasorelaxation in endothelium-removed rat superior mesenteric artery rings $(n=4-6)$. (a,b) These curves were constructed in the absence (control) and presence of tetraethylammonium (TEA; $1 \mathrm{mM})$. (c,d) These curves were constructed in the absence (control) and presence of (1) 4-aminopyridine (1 mM), (2) glibenclamide $(10 \mu \mathrm{M})$, (3) iberiotoxin (ibTX; $0.1 \mu \mathrm{M})+$ apamin $(0.1 \mu \mathrm{M})+$ TRAM-34 $(10 \mu \mathrm{M})$, and $(1)+(2)+(3)$. Results (mean \pm standard error of mean) are expressed as a percentage of the previous tone induced by phenylephrine $(1 \mu \mathrm{M}) .{ }^{*} p<0.05 \mathrm{vs}$. the control (Dunnett's test). 
a.

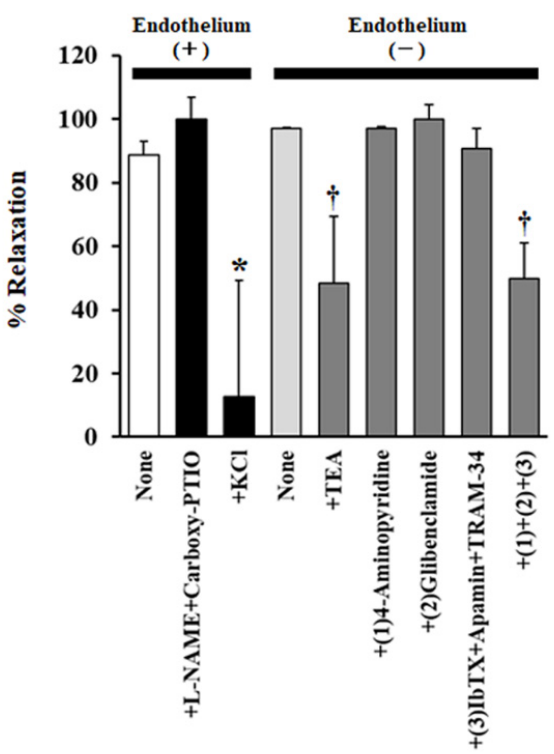

b.

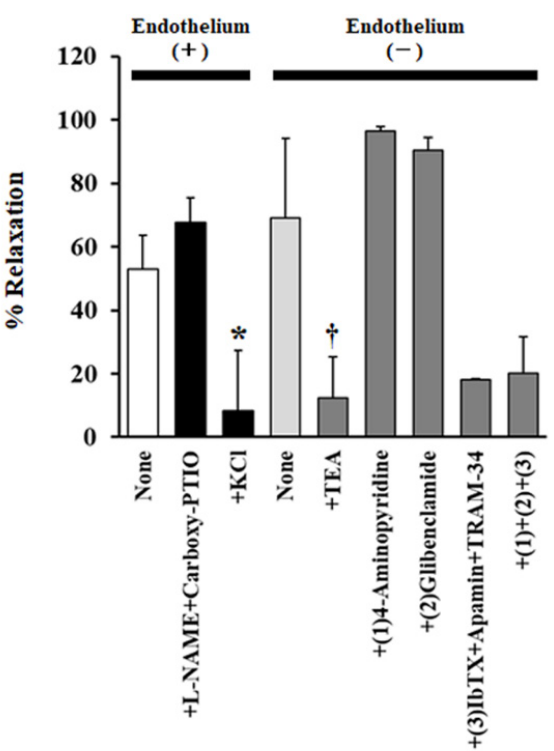

Figure 4. Effects of various inhibitors on (a) $0.1 \mathrm{~g} / \mathrm{L}$ persimmon juice- or (b) $0.3 \mathrm{~g} / \mathrm{L}$ persimmon leaf-induced vasorelaxation in rat superior mesenteric artery rings $(n=4-6)$. The inhibitors added were none, NG-nitro-L-arginine methyl ester (L-NAME $1 \mathrm{mM})+$ carboxy-PTIO $(0.1 \mathrm{mM})$, potassium chloride (20 mM), tetraethylammonium (TEA $1 \mathrm{mM}),(1)$ 4-aminopyridine (1 mM), (2) glibenclamide $(10 \mu \mathrm{M}),(3)$ iberiotoxin (ibTX $0.1 \mu \mathrm{M})+\operatorname{apamin}(0.1 \mu \mathrm{M})+$ TRAM-34 $(10 \mu \mathrm{M})$, and $(1)+(2)+(3)$. Results (mean \pm standard error of mean) are expressed as a percentage of the previous tone induced by phenylephrine $(1 \mu \mathrm{M}) .{ }^{*} p<0.05$ vs. none in the presence of endothelium (Dunnett's test). $+p<0.05$ vs. none in the absence of endothelium (Dunnett's test).

\subsection{Effect of PJ and PLs on Potassium Chloride- and Phenylephrine-Induced Vasocontraction}

Concentration-dependent vasocontraction due to potassium chloride via L-type $\mathrm{Ca}^{2+}$ channels was significantly suppressed by pretreatment with $1 \mathrm{~g} / \mathrm{L}$ PJ, but not PLs powder (Figure 5a, Table 2). On the other hand, concentration-dependent vasocontraction due to phenylephrine was significantly suppressed by pretreatment with both PJ and PLs powder (Figure 5b, Table 2).

a.

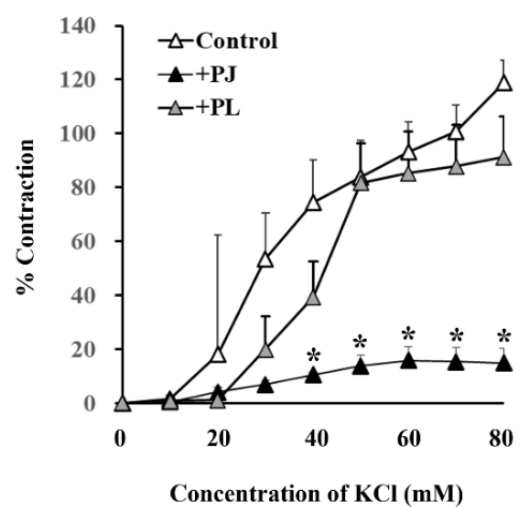

b.

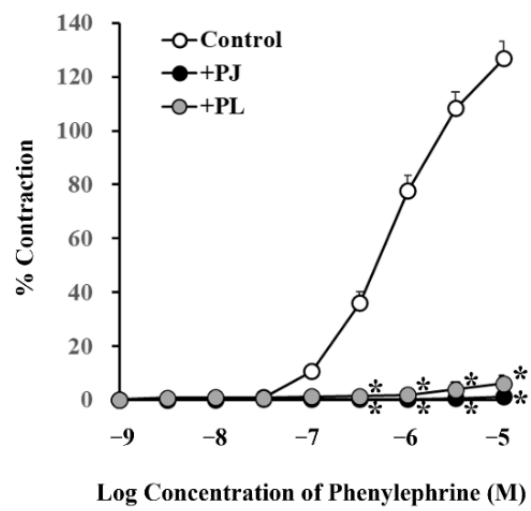

Figure 5. Concentration-response curves for (a) potassium chloride- and (b) phenylephrine-induced vasocontractions in rat superior mesenteric artery rings $(n=4-6)$. Curves were constructed for experiments with no pretreatment (control) and pretreatment with persimmon juice (PJ) $(1 \mathrm{~g} / \mathrm{L})$ and persimmon leaf (PLs) $(1 \mathrm{~g} / \mathrm{L})$ powder. Results (mean \pm standard error of mean) are expressed as a percentage of the previous tone induced by potassium chloride $(60 \mathrm{mM}){ }^{*} p<0.05 \mathrm{vs}$. each control (Dunnett's test). 
Table 2. Effects of persimmon juice (PJ) and persimmon leaf (PLs) pretreatment on potassium chloride- and phenylephrine-induced vasocontractions in rat superior mesenteric artery rings.

\begin{tabular}{ccccc}
\hline Pretreatment & \multicolumn{2}{c}{ Potassium Chloride $(\mathbf{8 0 ~} \mathbf{m M})$} & \multicolumn{2}{c}{ Phenylephrine $(\mathbf{1 0} \boldsymbol{\mu M})$} \\
\hline & \% Contraction & $\boldsymbol{p}$ Value & \% Contraction & $\boldsymbol{p}$ Value \\
\hline Control & $118.8 \pm 8.46$ & & $126.9 \pm 6.32$ & \\
$+\mathrm{PJ}(1 \mathrm{~g} / \mathrm{L})$ & $15.0 \pm 5.28^{*}$ & 0.00002 & $1.2 \pm 0.77^{*}$ & 0.000001 \\
$+\mathrm{PLs}(1 \mathrm{~g} / \mathrm{L})$ & $91.3 \pm 15.1$ & 0.10 & $6.1 \pm 3.02 *$ & 0.000001 \\
\hline
\end{tabular}

Contractions (mean \pm standard error of mean) are expressed as a percentage of the previous tone induced by potassium chloride $(60 \mathrm{mM}) .{ }^{*} p<0.05 \mathrm{vs}$. each control (Dunnett's test). $n=4-6$.

3.5. Effect of PJ and PLs on Phenylephrine-Induced Vasocontraction in the Presence of an Inhibitor of Intracellular Triphosphate-Mediated $\mathrm{Ca}^{2+}$ Release and in the Absence of $\mathrm{Ca}^{2+}$

Pretreatment with PJ and PLs powder significantly inhibited phenylephrine (300 nM-10 $\mu \mathrm{M}$ )-induced vasocontraction in the presence of $0.5 \mu \mathrm{M} \mathrm{XeC}$, a cell-permeable blocker of IP3-mediated $\mathrm{Ca}^{2+}$ release (Figure 6a, Table 3).

a.

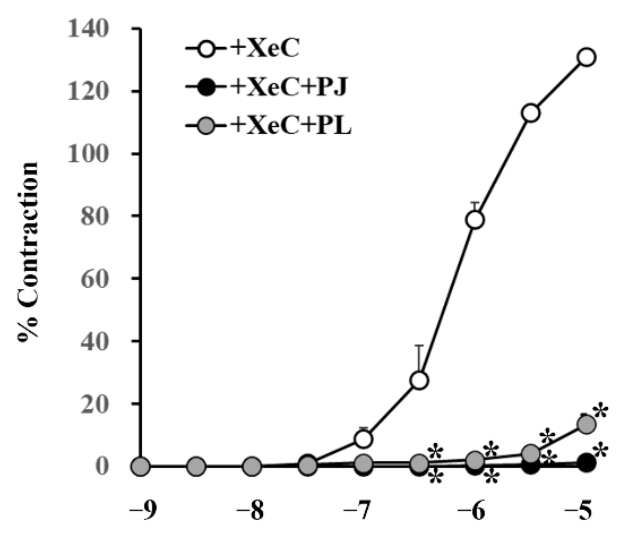

Log Concentration of Phenylephrine (M) b.

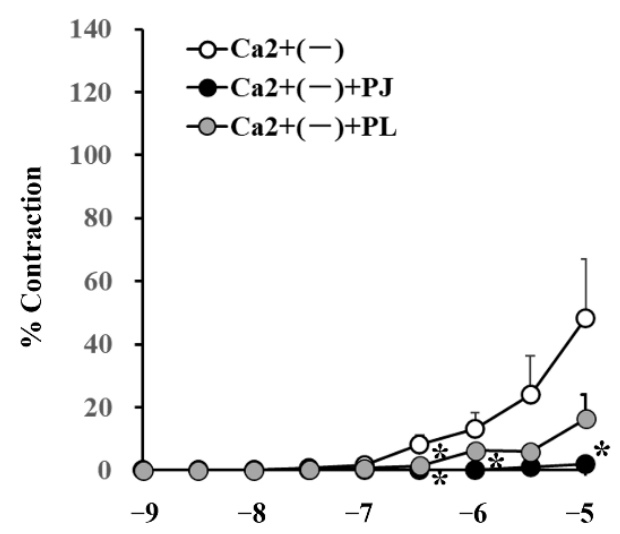

Log Concentration of Phenylephrine (M)

Figure 6. Concentration-response curves for phenylephrine-induced vasocontraction in the absence (control) or presence of pretreatment with persimmon juice (PJ) $(1 \mathrm{~g} / \mathrm{L}$ ) and persimmon leaf (PLs) $(1 \mathrm{~g} / \mathrm{L})$ powder in rat superior mesenteric artery rings $(n=4-6)$. (a) The curves were constructed for experiments in the presence of xestospongin $\mathrm{C}(\mathrm{XeC} ; 0.5 \mu \mathrm{M})$ and $(\mathbf{b})$ in the absence of $\mathrm{Ca}^{2+}$. Results (mean \pm standard error of mean) are expressed as a percentage of the previous tone induced by potassium chloride $(60 \mathrm{mM}) .{ }^{*} p<0.05$ vs. each control (Dunnett's test).

Table 3. Effects of persimmon juice (PJ) and persimmon leaf (PLs) pretreatment on phenylephrineinduced vasocontractions in the presence of xestospongin $\mathrm{C}(\mathrm{XeC})$ or in the absence of $\mathrm{Ca}^{2+}$ in rat superior mesenteric artery rings.

\begin{tabular}{ccc}
\hline Condition & \multicolumn{2}{c}{ Phenylephrine $(\mathbf{1 0} \mu \mathrm{M})$} \\
\hline & \% Contraction & $p$ Value \\
\hline$+\mathrm{XeC}(0.5 \mu \mathrm{M})$ & $130.8 \pm 2.32$ & 0.0001 \\
$+\mathrm{XeC}(0.5 \mu \mathrm{M})+\mathrm{PJ}(1 \mathrm{~g} / \mathrm{L})$ & $1.2 \pm 1.17^{*}$ & 0.0002 \\
$+\mathrm{XeC}(0.5 \mu \mathrm{M})+\mathrm{PLs}(1 \mathrm{~g} / \mathrm{L})$ & $13.5 \pm 2.91^{*}$ & \\
$\mathrm{Ca}^{2+}(-)$ & $48.2 \pm 18.9$ & 0.04 \\
$\mathrm{Ca}^{2+}(-)+\mathrm{PJ}(1 \mathrm{~g} / \mathrm{L})$ & $2.1 \pm 1.10^{*}$ & 0.14 \\
$\mathrm{Ca}^{2+}(-)+\mathrm{PLs}(1 \mathrm{~g} / \mathrm{L})$ & $16.4 \pm 7.48$ & \\
\hline
\end{tabular}

Contractions (mean \pm standard error of mean) are expressed as a percentage of the previous tone induced by potassium chloride $(60 \mathrm{mM}) .{ }^{*} p<0.05 \mathrm{vs}$. each control (Dunnett's test). $n=4-6$. 
Phenylephrine (300 nM, $1 \mu \mathrm{M}$, and $10 \mu \mathrm{M}$ )-induced vasocontraction in the absence of $\mathrm{Ca}^{2+}$, i.e., with inhibition of the influx of extracellular $\mathrm{Ca}^{2+}$ through the receptor-operated $\mathrm{Ca}^{2+}$ channels (ROCs), was significantly inhibited by pretreatment with PJ powder. In addition, phenylephrine (300 $\mathrm{nM})$-induced vasocontraction in the absence of $\mathrm{Ca}^{2+}$ was significantly inhibited by pretreatment with PLs powder (Figure 6b, Table 3).

\section{Discussion}

This study demonstrated that PJ- and PLs-derived polyphenol-induced vasorelaxation is not mediated by the endothelial cells, which differs from the results of previous reports. Generally, relaxation in conduit arteries, such as the aorta, is mainly mediated via NO release from the endothelium, and that in the peripheral arteries is mainly via EDHF [32,33]. In fact, many polyphenols reportedly induce NO- and EDHF-mediated relaxation of the endothelium [34,35]. However, in this study, PJ- and PLs-derived polyphenols yielded strong vasorelaxation at the smooth muscle level, but neither of these pathways was found related to this effect.

The effects of potassium-channel inhibitors on vasorelaxation induced by PJ- and PLsderived polyphenols were non-specific. Therefore, we hypothesize that these polyphenols cause hyperpolarization rather than activation of specific potassium channels. In fact, vasorelaxation induced by PJ- and PLs-derived polyphenols was inhibited by the addition of a depolarizing concentration $(20 \mathrm{mM})$ of potassium chloride, which was further supported by the fact that potassium chloride-induced vasocontraction was suppressed by PJ- and PLs-derived polyphenol pretreatment.

Polyphenols are known to suppress the vasocontraction caused by endothelin- 1 and angiotensin II [36-38]; however, to the best of our knowledge, this study is the first to demonstrate that PJ- and PLs-derived polyphenols suppress vasocontraction caused by phenylephrine. Pretreatment with PJ- and PLs-derived polyphenols suppressed phenylephrineinduced vasocontraction via both the ROC- and the IP3-mediated pathways. Hence, we hypothesize that these polyphenols cause hyperpolarization of the smooth muscle, thereby reducing the release of $\mathrm{Ca}^{2+}$ from the extracellular and intracellular stores of smooth muscle cells into the cytoplasm. In addition, as potassium chloride-induced vasocontraction via L-type $\mathrm{Ca}^{2+}$ channels was also suppressed by the PJ powder, it seems that suppression of vasocontraction induced by PJ-derived polyphenols was not receptor-specific.

The phytochemical characterization of the polyphenolic components of the persimmon cultivar used in this study, Hiratanenashi, have already been reported [39,40]. Highperformance liquid chromatography and mass spectrum analysis data show that persimmon fruits and leaves possess the catechin polymers, proanthocyanidin, which account for more than $90 \%$ of the total polyphenols in these fruits [40] and leaves [41]. Therefore, the vascular effects exerted by PJ and PLs in this study are primarily due to the monomeric and polymeric catechins, with minimal influence from other polyphenols. Moreover, the vascular reactivity of polyphenols derived from PJ was found to be higher than that of the polyphenols derived from PLs. This may, in part, be due to the fact that catechin concentration was more than 10 times higher in the former than in the latter. Second, the difference in the composition ratios of the four catechins EC, ECg, EGC, and EGCg in PJ and PLs may also be pivotal for the superior vascular effects of PJ compared to PLs.

As is frequently reported, all of these catechins have vasorelaxant effects. EGCg reportedly causes vascular endothelium-dependent, NO-mediated relaxation of the rat aorta [42]. EC reportedly causes relaxation in human saphenous veins by activating potassium channels in the smooth muscle [43], a mechanism consistent with the results of this study. In fact, we discovered the same relaxation and contraction-inhibitory effects with standard EGC in preliminary experiments (data not shown) as we did with PJ- and PLs-derived polyphenols. Therefore, the vascular activity of PJ- and PLs-derived polyphenols may be primarily due to the action of monomeric EC and EGC with a high composition ratio in both PJ and PLs. On the other hand, $\mathrm{Pu}$-erh tea reportedly causes vasorelaxation of rat aortas in an endotheliumindependent manner, partially via a reduction in the influx of extracellular $\mathrm{Ca}^{2+}$ induced by theabrownins, which are oxidatively polymerized rather than monomeric catechins [44]. 
Furthermore, PLs contain $40 \%$ or more of prodelphinidin, a catechin polymer that reportedly has a vasorelaxant effect [26]. Therefore, the vascular action of PJ and PLs shown in this study may be closely related not only to the monomeric catechins but also to the polymeric catechins produced in the fermentation process. The limitation of this study is that the difference in the structure and composition ratio of the polymeric catechins of PJ and PLs related to vascular action has not been clarified. Further research is needed to clarify the contribution of monomeric and polymeric catechins to the vascular effects of PJ and PLs.

Several experimental and clinical studies have revealed that polyphenols from certain fruits and vegetables reduce blood pressure [45-48]. As the antihypertensive effects of those polyphenols are mediated via vascular protection at the endothelial cell level [49-51], their antihypertensive effects may vary among individuals with cardiovascular disease depending on the degree of endothelial damage. On the other hand, in this study, we revealed that the putative hyperpolarization induced by PJ- and PLs-derived polyphenols acted on smooth muscle cells. Even if the endothelial cells are damaged by hypertension or arteriosclerosis, hyperpolarization will not be affected, which means that these polyphenols may confer a stable antihypertensive effect regardless of endothelial damage.

Furthermore, in this study, PJ- and PLs-derived polyphenols displayed functions similar to those of potassium-channel openers and $\mathrm{Ca}^{2+}$ antagonists, both of which are drug types indicated for heart failure. This suggests that persimmons may help ameliorate or prevent hypertension and cardiovascular disease as a functional food. Certain potassium channel openers reportedly reduce the $\mathrm{Ca}^{2+}$ sensitivity of contractile elements $\left(\mathrm{Ca}^{2+}\right.$ desensitization) in addition to reducing intracellular $\mathrm{Ca}^{2+}$ concentrations via hyperpolarization $[52,53]$. However, in this study, we did not investigate whether the hyperpolarization of vascular smooth muscle by PJ- and PLs-derived polyphenols reduces the $\mathrm{Ca}^{2+}$ sensitivity of contractile elements. Further studies are needed to elucidate the effects of PJ- and PLs-derived polyphenols on $\mathrm{Ca}^{2+}$ desensitization in vascular smooth muscle.

\section{Conclusions}

This study showed that PJ- and PLs-derived polyphenols have strong vasorelaxation and vasocontraction-inhibitory effects determined by the hyperpolarization of vascular smooth muscles. As these effects are not mediated via the endothelial release of $\mathrm{NO}$, PJ- and PLs-derived polyphenols may have a preventive effect on cardiovascular events not only in people with normal blood pressure, but also in those with hypertension and endothelial damage.

Author Contributions: Conceptualization, R.K., K.Y. and S.K.; methodology, R.K.; validation, R.K.; formal analysis, R.K. and K.Y.; investigation, R.K. and K.Y.; resources, R.K. and K.Y.; data curation, R.K.; writing—original draft preparation, R.K.; writing—review and editing, R.K.; visualization, R.K.; supervision, R.K.; project administration, R.K.; funding acquisition, R.K. All authors have read and agreed to the published version of the manuscript.

Funding: This research and the APC was funded by the Japan Society for the Promotion of Science KAKENHI, grant number 17K09273.

Institutional Review Board Statement: The study was conducted according to the policies established in the NIH Guide for the Care and Use of Laboratory Animals, and approved by the Animal Care Committee of Nara Medical University (No. 12689, obtained: 25 November 2019).

Informed Consent Statement: Not applicable.

Data Availability Statement: The data presented in this study are available on request from the corresponding author.

Acknowledgments: We would like to thank Ishii-Bussan, Inc. (Nara, Japan) for providing the persimmon juice and leaves powders.

Conflicts of Interest: The authors declare no conflict of interest. The funders had no role in the design of the study; in the collection, analyses, or interpretation of data; in the writing of the manuscript, or in the decision to publish the results. 


\section{References}

1. Khan, N.; Mukhtar, H. Tea Polyphenols in Promotion of Human Health. Nutrients 2018, 11, 39. [CrossRef] [PubMed]

2. Taguchi, K.; Hida, M.; Matsumoto, T.; Ikeuchi-Takahashi, Y.; Onishi, H.; Kobayashi, T. Effect of short-term polyphenol treatment on endothelial dysfunction and thromboxane A2 levels in streptozotocin-induced diabetic mice. Biol. Pharm. Bull. 2014, 37, 1056-1061. [CrossRef] [PubMed]

3. Munir, K.M.; Chandrasekaran, S.; Gao, F.; Quon, M.J. Mechanisms for food polyphenols to ameliorate insulin resistance and endothelial dysfunction: Therapeutic implications for diabetes and its cardiovascular complications. Am. J. Physiol. Endocrinol. Metab. 2013, 305, 679-686. [CrossRef] [PubMed]

4. Van Dam, R.M.; Naidoo, N.; Landberg, R. Dietary flavonoids and the development of type 2 diabetes and cardiovascular diseases: Review of recent findings. Curr. Opin. Lipidol. 2013, 24, 25-33. [CrossRef] [PubMed]

5. Quiñones, M.; Miguel, M.; Aleixandre, A. Beneficial effects of polyphenols on cardiovascular disease. Pharmacol. Res. 2013, 68, 125-131. [CrossRef]

6. Sies, H. Polyphenols and health: Update and perspectives. Arch. Biochem. Biophys. 2010, 501, 2-5. [CrossRef]

7. Andrade, A.C.; Cesena, F.H.; Consolim-Colombo, F.M.; Coimbra, S.R.; Benjó, A.M.; Krieger, E.M.; Luz, P.L. Short-term red wine consumption promotes differential effects on plasma levels of high-density lipoprotein cholesterol, sympathetic activity, and endothelial function in hypercholesterolemic, hypertensive, and healthy subjects. Clinics 2009, 64, 435-442. [CrossRef]

8. Chaves, A.A.; Joshi, M.S.; Coyle, C.M.; Brady, J.E.; Dech, S.J.; Schanbacher, B.L.; Baliga, R.; Basuray, A.; Bauer, J.A. Vasoprotective endothelial effects of a standardized grape product in humans. Vascul. Pharmacol. 2009, 50, 20-26. [CrossRef]

9. Coimbra, S.R.; Lage, S.H.; Brandizzi, L.; Yoshida, V.; Da Luz, P.L. The action of red wine and purple grape juice on vascular reactivity is independent of plasma lipids in hypercholesterolemic patients. Braz. J. Med. Biol. Res. 2005, 38, 1339-1347. [CrossRef]

10. Zhang, Q.; Yuan, H.; Zhang, C.; Guan, Y.; Wu, Y.; Ling, F.; Niu, Y.; Li, Y. Epigallocatechin gallate improves insulin resistance in HepG2 cells through alleviating inflammation and lipotoxicity. Diabetes Res. Clin. Pract. 2018, 142, 363-373. [CrossRef]

11. Mi, Y.; Liu, X.; Tian, H.; Liu, H.; Li, J.; Qi, G.; Liu, X. EGCG stimulates the recruitment of brite adipocytes, suppresses adipogenesis and counteracts TNF- $\alpha$-triggered insulin resistance in adipocytes. Food Funct. 2018, 9, 3374-3386. [CrossRef] [PubMed]

12. Yamagata, K. Polyphenols Regulate Endothelial Functions and Reduce the Risk of Cardiovascular Disease. Curr. Pharm. Des. 2019, 25, 2443-2458. [CrossRef]

13. Li, H.; Xia, N.; Hasselwander, S.; Daiber, A. Resveratrol and Vascular Function. Int. J. Mol. Sci. 2019, 20, 2155. [CrossRef]

14. Matsumoto, T.; Watanabe, S.; Kawamura, R.; Taguchi, K.; Kobayashi, T. Epigallocatechin gallate attenuates ET-1-induced contraction in carotid artery from type 2 diabetic OLETF rat at chronic stage of disease. Life Sci. 2014, 118, 200-205. [CrossRef] [PubMed]

15. Rodrigo, R.; Gil, D.; Miranda-Merchak, A.; Kalantzidis, G. Antihypertensive role of polyphenols. Adv. Clin. Chem. 2012, 58, 225-254. [CrossRef]

16. Dal-Ros, S.; Bronner, C.; Schott, C.; Kane, M.O.; Chataigneau, M.; Schini-Kerth, V.B.; Chataigneau, T. Angiotensin II-induced hypertension is associated with a selective inhibition of endothelium-derived hyperpolarizing factor-mediated responses in the rat mesenteric artery. J. Pharmacol. Exp. Ther. 2009, 328, 478-486. [CrossRef] [PubMed]

17. Kwak, C.J.; Kubo, E.; Fujii, K.; Nishimura, Y.; Kobuchi, S.; Ohkita, M.; Yoshimura, M.; Kiso, Y.; Matsumura, Y. Antihypertensive effect of French maritime pine bark extract (Flavangenol): Possible involvement of endothelial nitric oxide-dependent vasorelaxation. J. Hypertens. 2009, 27, 92-101. [CrossRef]

18. Anselm, E.; Socorro, V.F.; Dal-Ros, S.; Schott, C.; Bronner, C.; Schini-Kerth, V.B. Crataegus special extract WS 1442 causes endothelium-dependent relaxation via a redox-sensitive Src- and Akt-dependent activation of endothelial NO synthase but not via activation of estrogen receptors. J. Cardiovasc. Pharmacol. 2009, 53, 253-260. [CrossRef]

19. Andriambeloson, E.; Kleschyov, A.L.; Muller, B.; Beretz, A.; Stoclet, J.C.; Andriantsitohaina, R. Nitric oxide production and endothelium-dependent vasorelaxation induced by wine polyphenols in rat aorta. Br. J. Pharmacol. 1997, 120, 1053-1058. [CrossRef]

20. Rocha, A.P.; Carvalho, L.C.; Sousa, M.A.; Madeira, S.V.; Sousa, P.J.; Tano, T.; Schini-Kerth, V.B.; Resende, A.C.; Soares de Moura, R. Endothelium-dependent vasodilator effect of Euterpe oleracea Mart. (Açaí) extracts in mesenteric vascular bed of the rat. Vascul. Pharmacol. 2007, 46, 97-104. [CrossRef]

21. Anselm, E.; Chataigneau, M.; Ndiaye, M.; Chataigneau, T.; Schini-Kerth, V.B. Grape juice causes endothelium-dependent relaxation via a redox-sensitive Src- and Akt-dependent activation of eNOS. Cardiovasc. Res. 2007, 73, 404-413. [CrossRef] [PubMed]

22. Ndiaye, M.; Chataigneau, T.; Chataigneau, M.; Schini-Kerth, V.B. Red wine polyphenols induce EDHF-mediated relaxations in porcine coronary arteries through the redox-sensitive activation of the PI3-kinase/Akt pathway. Br. J. Pharmacol. 2004, 142, 1131-1136. [CrossRef] [PubMed]

23. Miao, M.; Zhang, X.; Bai, M.; Wang, L. Persimmon leaf flavonoid promotes brain ischemic tolerance. Neural Regen. Res. 2013, 8 , 2625-2632. [CrossRef] [PubMed]

24. Gao, Y.F.; Gao, Y.S.; Xin, X.M. Hypoglycemic and hypocholesterolaemia effect of total flavonoids from persimmon leaf in alloxan-induced diabetic mice and its mechanism. Taishan Yixueyuan Xuebao 2009, 30, 245-247.

25. Xin, N.; Feng, J.; Yao, B. Extraction, separation and pharmacological effects of total flavonoids from persimmon leaf. Zhongyiyao Xuebao 2007, 2, 49-51. 
26. Kawakami, K.; Aketa, S.; Sakai, H.; Watanabe, Y.; Nishida, H.; Hirayama, M. Antihypertensive and vasorelaxant effects of water-soluble proanthocyanidins from persimmon leaf tea in spontaneously hypertensive rats. Biosci. Biotechnol. Biochem. 2011, 75, 1435-1439. [CrossRef]

27. Iwase, K.; Torii, H. A colorimetric determination of tea tannin with ferrous tartrate. Tea Res. J. (Chagyo Kenkyu Hokoku) 1962, 19, 104-108. [CrossRef]

28. Usui, K.; Murata, T.; Fujita, Y.; Kamijo, Y.; Hanazawa, T.; Yoshizawa, T.; Funayama, M. Direct detection of the psychoactive substance MT-45 in human tissue samples by probe electrospray ionization-tandem mass spectrometry. Drug Test. Anal. 2018, 10, 1033-1038. [CrossRef]

29. Wang, C.Y.; Li, Q.S.; Han, G.Z.; Zou, L.L.; Lv, L.; Zhou, Q.; Li, N. LC-MS/MS for simultaneous determination of four major active catechins of tea polyphenols in rat plasma and its application to pharmacokinetics. Chin. Herb. Med. 2010, 2, $289-296$.

30. Yuui, K.; Kudo, R.; Kasuda, S.; Hatake, K. Ethanol attenuates vasorelaxation via inhibition of inducible nitric oxide synthase in rat artery exposed to interleukin-1ß. Hum. Exp. Toxicol. 2016, 35, 938-945. [CrossRef]

31. Kudo, R.; Yuui, K.; Kasuda, S.; Nakata, M.; Imai, H.; Nakanishi, M.; Hatake, K. Effect of ethanol on capsaicin-induced nervemediated vasorelaxation in rat arteries. Rom. J. Legal Med. 2017, 25, 1-7. [CrossRef]

32. Shimokawa, H.; Yasutake, H.; Fujii, K.; Owada, M.K.; Nakaike, R.; Fukumoto, Y.; Takayanagi, T.; Nagao, T.; Egashira, K.; Fujishima, M.; et al. The importance of the hyperpolarizing mechanism increases as the vessel size decreases in endotheliumdependent relaxations in rat mesenteric circulation. J. Cardiovasc. Pharmacol. 1996, 28, 703-711. [CrossRef]

33. Nagao, T.; Illiano, S.; Vanhoutte, P.M. Heterogeneous distribution of endothelium-dependent relaxations resistant to $\mathrm{N}^{\mathrm{G}}$-nitro-Larginine in rats. Am. J. Physiol. 1992, 263, H1090-H1094. [CrossRef]

34. Schini-Kerth, V.B.; Auger, C.; Kim, J.H.; Etienne-Selloum, N.; Chataigneau, T. Nutritional improvement of the endothelial control of vascular tone by polyphenols: Role of NO and EDHF. Pflugers. Arch. 2010, 459, 853-862. [CrossRef]

35. Schini-Kerth, V.B.; Auger, C.; Etienne-Selloum, N.; Chataigneau, T. Polyphenol-induced endothelium-dependent relaxations role of NO and EDHF. Adv. Pharmacol. 2010, 60, 133-175. [CrossRef] [PubMed]

36. López-Sepúlveda, R.; Gómez-Guzmán, M.; Zarzuelo, M.J.; Romero, M.; Sánchez, M.; Quintela, A.M.; Galindo, P.; O’Valle, F.; Tamargo, J.; Pérez-Vizcaíno, F.; et al. Red wine polyphenols prevent endothelial dysfunction induced by endothelin-1 in rat aorta: Role of NADPH oxidase. Clin. Sci. 2011, 120, 321-333. [CrossRef]

37. Reiter, C.N.; Kim, J.; Quon, M.J. Green tea polyphenol epigallocatechin gallate reduces endothelin-1 expression and secretion in vascular endothelial cells: Roles for AMP-activated protein kinase, Akt, and FOXO1. Endocrinology 2010, 151, 103-114. [CrossRef]

38. Kane, M.O.; Etienne-Selloum, N.; Madeira, S.F.; Sarr, M.; Walter, A.; Dal-Ros, S.; Schott, C.; Chataigneau, T.; Schini-Kerth, V.B Endothelium-derived contracting factors mediate the Ang II-induced endothelial dysfunction in the rat aorta: Preventive effect of red wine polyphenols. Pflug. Arch. 2010, 459, 671-679. [CrossRef] [PubMed]

39. Kometani, T.; Takemori, K. Polyphenols from Persimmon Fruits as a Functional Foods Material. Nippon Shokuhin Kagaku Kogaku Kaishi 2016, 63, 331-337. [CrossRef]

40. Matsuo, T.; Ito, S. The chemical structure of kaki-tannin from immature fruit of the persimmon (Diospyros kaki L.). Agric. Biol. Chem. 1978, 42, 1637-1643.

41. Kawakami, K.; Aketa, S.; Nakanami, M.; Iizuka, S.; Hirayama, M. Major water-soluble polyphenols, proanthocyanidins, in leaves of persimmon (Diospyros kaki) and their alpha-amylase inhibitory activity. Biosci. Biotechnol. Biochem. 2010, 74, 1380-1385. [CrossRef] [PubMed]

42. Lorenz, M.; Wessler, S.; Follmann, E.; Michaelis, W.; Düsterhöft, T.; Baumann, G.; Stangl, K.; Stangl, V. A constituent of green tea, epigallocatechin-3-gallate, activates endothelial nitric oxide synthase by a phosphatidylinositol-3-OH-kinase-, cAMP-dependent protein kinase-, and Akt-dependent pathway and leads to endothelial-dependent vasorelaxation. J. Biol. Chem. 2004, 279, 6190-6195. [CrossRef] [PubMed]

43. Marinko, M.; Jankovic, G.; Nenezic, D.; Milojevic, P.; Stojanovic, I.; Kanjuh, V.; Novakovic, A. (-)-Epicatechin-induced relaxation of isolated human saphenous vein: Roles of $\mathrm{K}^{+}$and $\mathrm{Ca}^{2+}$ channels. Phytother. Res. 2018, 32, 267-275. [CrossRef]

44. Luo, D.; Chen, X.; Zhu, X.; Liu, S.; Li, J.; Xu, J.; Zhao, J.; Ji, X. Pu-Erh Tea Relaxes the Thoracic Aorta of Rats by Reducing Intracellular Calcium. Front. Pharmacol. 2019, 10, 1430. [CrossRef] [PubMed]

45. Desch, S.; Schmidt, J.; Kobler, D.; Sonnabend, M.; Eitel, I.; Sareban, M.; Rahimi, K.; Schuler, G.; Thiele, H. Effect of cocoa products on blood pressure: Systematic review and meta-analysis. Am. J. Hypertens. 2010, 23, 97-103. [CrossRef]

46. Balzer, J.; Rassaf, T.; Heiss, C.; Kleinbongard, P.; Lauer, T.; Merx, M.; Heussen, N.; Gross, H.B.; Keen, C.L.; Schroeter, H.; et al. Sustained benefits in vascular function through flavanol-containing cocoa in medicated diabetic patients a double-masked, randomized, controlled trial. J. Am. Coll. Cardiol. 2008, 51, 2141-2149. [CrossRef] [PubMed]

47. Grassi, D.; Desideri, G.; Necozione, S.; Lippi, C.; Casale, R.; Properzi, G.; Blumberg, J.B.; Ferri, C. Blood pressure is reduced and insulin sensitivity increased in glucose-intolerant, hypertensive subjects after 15 days of consuming high-polyphenol dark chocolate. J. Nutr. 2008, 138, 1671-1676. [CrossRef] [PubMed]

48. Hooper, L.; Kroon, P.A.; Rimm, E.B.; Cohn, J.S.; Harvey, I.; Le Cornu, K.A.; Ryder, J.J.; Hall, W.L.; Cassidy, A. Flavonoids, flavonoid-rich foods, and cardiovascular risk: A meta-analysis of randomized controlled trials. Am. J. Clin. Nutr. 2008, 88, 38-50. [CrossRef] [PubMed]

49. Ghosh, D.; Scheepens, A. Vascular action of polyphenols. Mol. Nutr. Food. Res. 2009, 53, 322-331. [CrossRef] [PubMed] 
50. Lorenz, M.; Urban, J.; Engelhardt, U.; Baumann, G.; Stangl, K.; Stangl, V. Green and black tea are equally potent stimuli of NO production and vasodilation: New insights into tea ingredients involved. Basic Res. Cardiol. 2009, 104, 100-110. [CrossRef]

51. Duffy, S.J.; Keaney, J.F., Jr.; Holbrook, M.; Gokce, N.; Swerdloff, P.L.; Frei, B.; Vita, J.A. Short- and long-term black tea consumption reverses endothelial dysfunction in patients with coronary artery disease. Circulation 2001, 104, 151-156. [CrossRef] [PubMed]

52. Okada, Y.; Yanagisawa, T.; Taira, N. BRL 38227 (levcromakalim)-induced hyperpolarization reduces the sensitivity to Ca ${ }^{2+}$ of contractile elements in canine coronary artery. Naunyn Schmiedebergs Arch. Pharmacol. 1993, 347, 438-444. [CrossRef] [PubMed]

53. Okada, Y.; Yanagisawa, T.; Yamagishi, T.; Taira, N. $\mathrm{K}^{+}$channel-opening action and KRN2391-induced reduction of $\mathrm{Ca}^{2+}$ sensitivity of arterial smooth muscle. Arch. Int. Pharmacodyn. Ther. 1993, 326, 33-51. [PubMed] 